\title{
Continuous Fabrication and Assembly of Spatial Cell-Laden Fibers for a Tissue-Like Construct via a Photolithographic-Based Microfluidic Chip
}

\author{
Dan Wei, ${ }^{\dagger, \ddagger \odot ~ J i n g ~ S u n, ~}{ }^{\dagger, \ddagger}$ Jason Bolderson, ${ }^{\S}$ Meiling Zhong, ${ }^{\dagger}$ Matthew John Dalby, ${ }^{\perp}$ Maggie Cusack, ${ }^{\|}$ \\ Huabing Yin, ${ }^{*} \S$ Hongsong Fan, ${ }^{*} \dagger$ a and Xingdong Zhang \\ ${ }^{\dagger}$ National Engineering Research Center for Biomaterials, Sichuan University, Chengdu 610064, Sichuan, China \\ ${ }^{\S}$ Division of Biomedical Engineering, School of Engineering, University of Glasgow, Glasgow G12 8LT, U.K. \\ ${ }^{\perp}$ Centre for Cell Engineering, College of Medical, Veterinary and Life Sciences, and "School of Geographical and Earth Science, \\ University of Glasgow, Glasgow G12 8QQ U.K.
}

Supporting Information

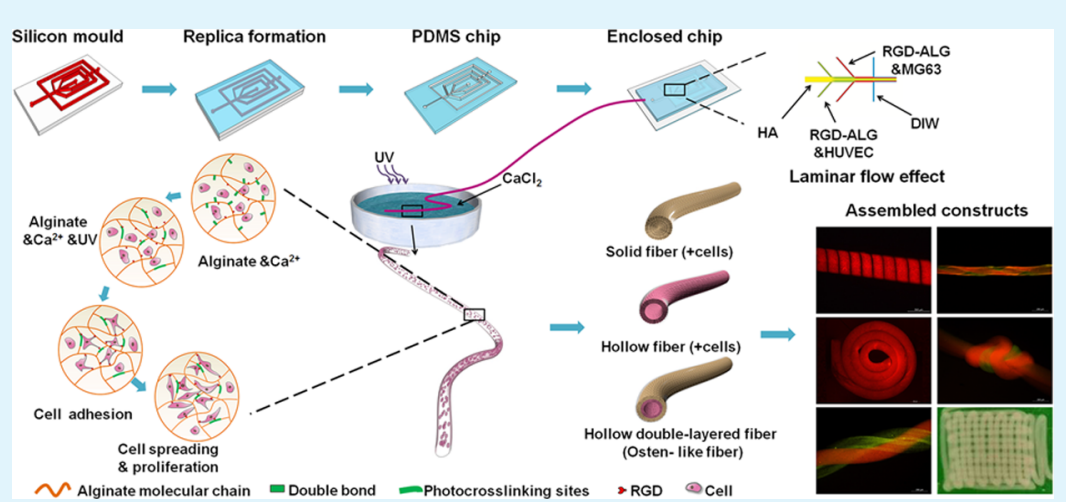

ABSTRACT: Engineering three-dimensional (3D) scaffolds with in vivo like architecture and function has shown great potential for tissue regeneration. Here we developed a facile microfluidic-based strategy for the continuous fabrication of cell-laden microfibers with hierarchically organized architecture. We show that photolithographically fabricated microfluidic devices offer a simple and reliable way to create anatomically inspired complex structures. Furthermore, the use of photo-cross-linkable methacrylated alginate allows modulation of both the mechanical properties and biological activity of the hydrogels for targeted applications. Via this approach, multilayered hollow microfibers were continuously fabricated, which can be easily assembled in situ, using 3D printing, into a larger, tissue-like construct. Importantly, this biomimetic approach promoted the development of phenotypical functions of the target tissue. As a model to engineer a complex tissue construct, osteon-like fiber was biomimetically engineered, and enhanced vasculogenic and osteogenic expression were observed in the encapsulated human umbilical cord vein endothelial cells and osteoblast-like MG63 cells respectively within the osteon fibers. The capability of this approach to create functional building blocks will be advantageous for bottom-up regeneration of complex, large tissue defects and, more broadly, will benefit a variety of applications in tissue engineering and biomedical research.

KEYWORDS: microfluidic, cell-laden hydrogel, microscale tissue engineering, osteon-like, biofabrication

\section{INTRODUCTION}

In the past decade, the fabrication of three-dimensional (3D) scaffolds with in vivo like architecture and function has shown great potential for tissue regeneration. ${ }^{1-4}$ However, in the body, tissues comprise multiple cell types that are hierarchically organized within a complex extracellular matrix (ECM)., Therefore, the regeneration of functional tissues not only depends on the capability of controlling biocompatible ECM complexities at the nano/microscale but also requires the ability of the components to assemble into larger length scales.

To date, photolithographic-based methods have been well established for controlling cell shape, cell-cell interaction, and spatial organization at the microscale level on two-dimensional
(2D) surfaces $^{7-9}$ or in 3D matrixes. ${ }^{10-12}$ Although these approaches offer great flexibility to generate individual microstructures of desirable architecture and properties, assembling the microunits into a larger construct is difficult and unreliable, thus imposing a significant challenge for its wide implementation in tissue regeneration. ${ }^{12-14}$

An alternative approach exploits microfluidic technology to create 3D microstructures that have the distinct advantage of versatility and high throughput. ${ }^{15,16} \mathrm{~A}$ vast range of acellular

Received: January 3, 2017

Accepted: February 3, 2017

Published: February 3, 2017 


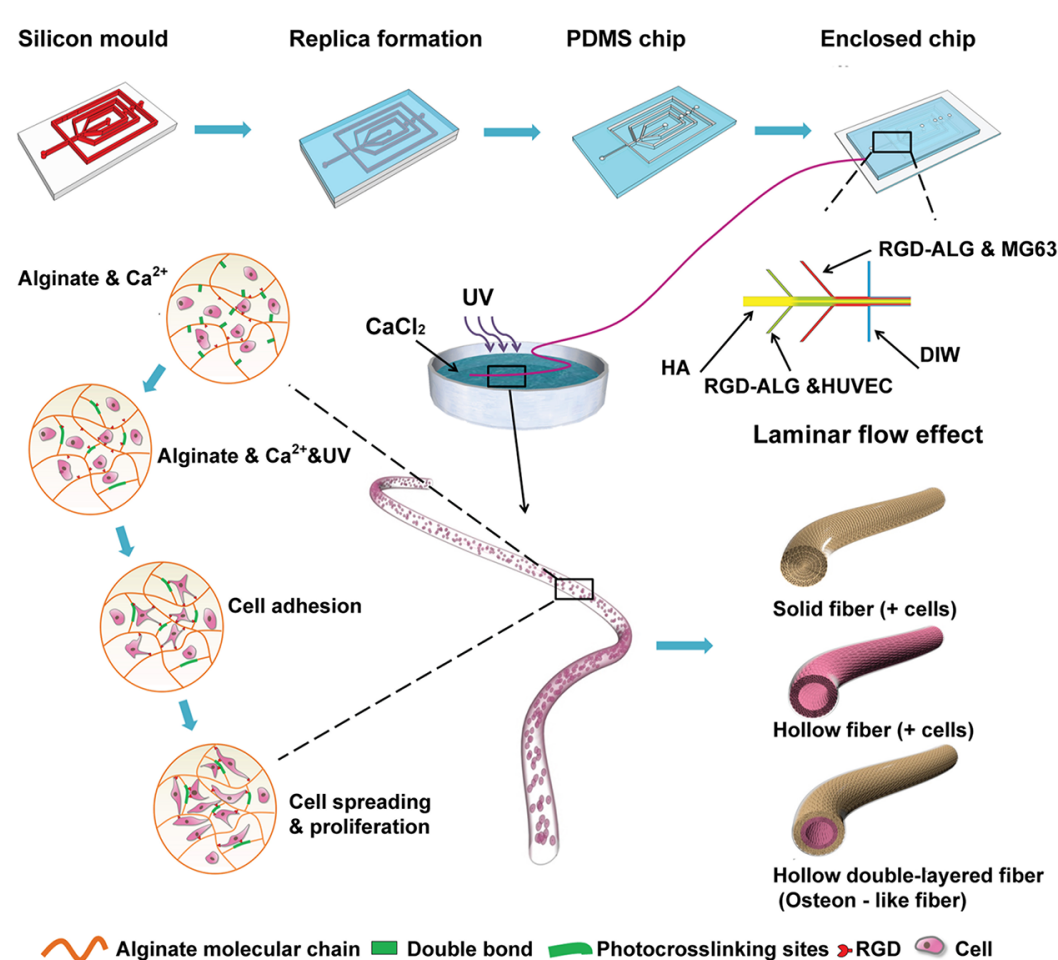

Figure 1. Schematic drawing of the fabrication of a microfluidic chip and continuous extrusion of various microfibers of different shapes using RGDmodified alginate.

biomaterials, such as multifunctional microparticles ${ }^{17}$ and microfibers, ${ }^{18-21}$ have been fabricated using microfluidic devices. Recent rapid development in microfluidic spinning of cell-laden microfibers demonstrates how fiber-shaped building blocks are advantageous in forming hierarchical structures such as blood vessels and vascular networks for large engineered constructs. $^{22}$ A number of microfibers of different shapes, e.g., solid, tubular, and square of diverse dimensions, have been created. ${ }^{21,23-26}$ The assembly of microscale microfibers into mesoscale structures has been achieved via traditional textile techniques, such as winding, bonding, and weaving. ${ }^{27}$

However, the development of cell-laden fibers is still at an early stage and is significantly limited by the challenges of handling living cells that require low shear stress and benign conditions and the shortage of suitable biomaterials for fast microfluidic processing. To date, the majority of work employs capillary-based microfluidic devices to generate coaxial flows and on-chip gelation for creating microfibers. ${ }^{21,28,29}$ However, the fabrication of capillary-based devices is labor-intensive and highly skilled. ${ }^{21}$ In contrast, photolithographic technology can fabricate poly(dimethylsiloxane) (PDMS) chips of complex structure precisely and reliably through a molding process. Surprisingly, there are few examples of this photolithographic PDMS chip to create cell-laden microfibers ${ }^{23,30}$ and there has been little work done on complex cell-laden microfibers with more than three layers.

Another challenge for developing functional microfibers lies in the lack of suitable materials with sufficient biological activities. So far, microfibers have been mainly fabricated out of the alginate hydrogel because of its rapid gelation process in the presence of divalent cations. ${ }^{28,31-33}$ However, alginate lacks cell adhesion sites and does not promote cell spreading. In addition, alginate can disintegrate in a common culture medium at a low $\mathrm{Ca}^{2+}$ concentration. ${ }^{34}$ As a consequence, most previous work has only reported the viability of cells encapsulated within alginate-based microfibers, rarely involving the considerable spreading and function enchantment of cells. ${ }^{20,21,23,35}$ In contrast, hydrogels from natural ECM such as gelatin and collagen can provide cells with a more biomimetic microenvironment. However, their gelation takes hours, which is too slow to match the rapidity of the microfluidic spinning process, which is a matter of seconds. Recently, Onoe et al. ${ }^{27}$ developed a double-coaxial flow capillary device to construct cellcontaining ECM protein/calcium alginate core-shell microfibers. The outer calcium alginate shell provided temporary mechanical support for the microfibers, whereas the subsequently formed cell-containing ECM microfibers induced a certain level of physiological function of the encapsulated cells. Although this approach is viable for creating simple doublelayered microfibers, the fabrication of more complex structures would require many stages of assembly of glass capillaries, which is not technically practical. The formation of physiologically functional microfibers with an organized microscale structure akin to living tissues is yet to be realized.

In this work, we demonstrate a facile microfluidic-based strategy for continuous fabrication of cell-laden microfibers with a hierarchically organized architecture. Photolithographic technology was employed to fabricate the microfluidic devices, allowing multistage networks to be constructed in a single step. This approach offers great flexibility to create anatomically inspired complex structures. The formation of replica methods using PDMS provides a route to disposable devices. Furthermore, UV-cross-linkable methacrylated alginate was employed $^{36,37}$ to enhance the mechanical properties of the gel and promote cell adhesion via the grafting of RGD (ArgGly-Asp) peptides by means of a Michael addition reaction. With this microfluidic approach, hollow and solid microfibers of well-controlled multilayer structures were continuously fabricated and automatically assembled into a larger, tissue-like construct. As a demonstration of this approach, we fabricated 
osteon-like microfibers (denoted as the osteon fiber) that contain spatially organized human umbilical cord vein endothelial cells (HUVECs) and MG63 cells, as shown in Figure 1. The cell morphology, viability, and genetic expression were evaluated for 3 weeks in a culture. In comparison to single-cell-type fibers, increased expression levels of osteogenic and vasculogenic genes were observed in the osteon fibers, demonstrating the efficacy of this biomimetic approach to induce phenotypic functions of cells. These functional building blocks will be advantageous for the bottom-up regeneration of complex, large tissue defects.

\section{RESULTS AND DISCUSSION}

2.1. Characterization of the Functionalized Alginate Hydrogel. The gelation of methacrylated alginate can occur via ionic cross-linking of the alginate backbone or UV-initiated polymerization due to the methacrylate groups. Both crosslinking methods were employed here, where ionic cross-linking allows instant solidification of extruded liquid phases and photopolymerization maintains the structure of solidified fibers without the need for divalent cations in the culture medium. To evaluate the effect of cross-linking on the mechanical properties, compressive moduli of a series of bulk hydrogels prepared at various conditions (Table 1) were characterized. As

Table 1. Compositions of Different Hydrogel Formations

\begin{tabular}{lcl}
\multicolumn{1}{c}{ material } & $\begin{array}{c}\text { methacrylated alginate concentration } \\
\left(\mathrm{mg} \mathrm{L}^{-1}\right)\end{array}$ & $\begin{array}{c}\text { gelation } \\
\text { conditions }\end{array}$ \\
\hline ALG-no-UV & 15 & $\mathrm{Ca}^{2+}$ \\
ALG & 15 & $\mathrm{Ca}^{2+}, \mathrm{UV}$ \\
RGD-ALG & 15 & $\mathrm{Ca}^{2+}, \mathrm{UV}$ \\
\hline
\end{tabular}

shown in Figure 2A, there is no significant difference between the methacrylated alginate hydrogel cross-linked via $\mathrm{Ca}^{2+}$ ions only (denoted as ALG-no-UV, $20.07 \pm 3.34 \mathrm{kPa}$ ) and that cross-linked initially via $\mathrm{Ca}^{2+}$ ions and then by UV photo-crosslinking (denoted as ALG, $22.66 \pm 2.42 \mathrm{kPa}$ ). The ALG microfibers maintained their fibrous shape throughout the whole period of culture, which is beneficial to further assembly operations. In contrast, with the dissolution of $\mathrm{Ca}^{2+}$ ions, an ALG-no-UV hydrogel microfiber was broken easily after $6 \mathrm{~h}$ in a culture medium, if a slight stirring or other operation was applied (Figure 2B). The introduction of RGD into the methacrylated alginate resulted in a lower mechanical strength of the RGD-ALG hydrogel $(17.34 \pm 1.61 \mathrm{kPa}$; Figure $2 \mathrm{~A}$; *, $p$ $<0.05)$, mainly because the grafting of RGD reduced the number of methacrylate groups available for cross-linking. Similar to the ALG microfibers, the RGD-ALG microfibers maintained their shape in the culture medium (Figure 2B). These results prove that the combination of ionic and photoinitiated cross-linking is effective for the production of microfibers with structural stability over long periods of culture.

RGD peptides are well-known integrin binding sites that can promote cell adhesion. ${ }^{38}$ As shown in Figure 2C,D, MG63 cells encapsulated in the RGD-ALG hydrogel showed better proliferation and spreading than those in the ALG hydrogel. After 5 days in a culture, a considerable number of MG63 cells spread extensively inside the RGD-ALG hydrogel, forming a spindlelike morphology and direct cell-cell contacts (Supporting Information, Figure S1). In contrast, almost all MG63 cells in the ALG hydrogel were rounded (Figure 2C). This indicates that the incorporation of RGD into the alginate hydrogel significantly enhanced cell adhesion and the biological activities of the inert alginate materials.

2.2. Continuous Fabrication and Multiscale Assembly of Microfibers. Hollow multilayered hydrogel microfibers were fabricated via microfluidic extrusion in conjunction with the combined ionic and UV cross-linking. As illustrated in Figure 1, different solutions were introduced to the microfluidic chip through the respective inlets, where a hyaluronic acid (HA) solution of considerable viscosity (Table 2) was
A

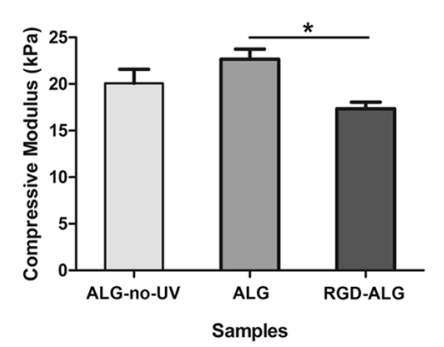

B

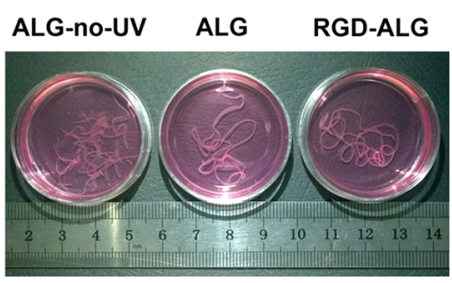

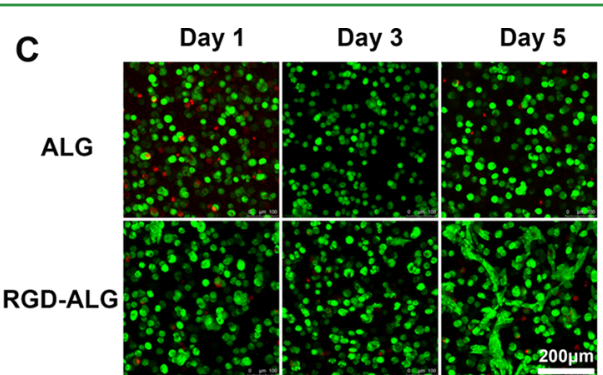

D

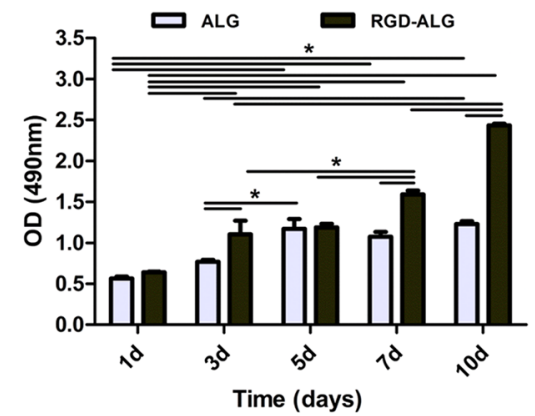

Figure 2. (A) Compressive moduli of ALG-no-UV, ALG, and RGD-ALG bulk hydrogels. (B) Photographs of ALG-no-UV, ALG, and RGD-ALG hydrogel microfibers after $6 \mathrm{~h}$ in a culture medium with slight stirring. (C) Fluorescence images of MG63 cells encapsulated in various bulk hydrogels with live and dead (i.e., FDA/PI) staining during the period of culture. (D) MTT analysis of the MG63 cells encapsulated in the bulk hydrogels $(*, p<0.05)$. 
Table 2. Viscosities of Different Solutions

\begin{tabular}{lcc} 
material & concentration $\left(\mathrm{mg} \mathrm{L}^{-1}\right)$ & viscosity $(\mathrm{Pa} \cdot \mathrm{s})$ \\
ALG & 15 & 1.63 \\
RGD-ALG & 15 & 1.86 \\
HA & 20 & 4.01 \\
\hline
\end{tabular}

introduced to the innermost channel to form the hollow lumen because the non-cross-linked HA solution would be dissolved in the bath during the culture time, different alginate solutions (ALG) were introduced to the side channels to form individual layers, and deionized water (DIW) was introduced to the outermost side channel to reduce the friction between the alginate solution and chip wall. All solutions were delivered continuously to the chip via syringe pumps at a range of rates $\left(<30 \mu \mathrm{L} \mathrm{min}{ }^{-1}\right)$. At these conditions, laminar flow dominated (Reynolds number $<0.01$ ), which gave rise to stable interfaces between each stream and consequently stabilized their structures on the chip. Extrusion of the liquid format of microfibers through a short plastic tube into a $0.1 \mathrm{M} \mathrm{CaCl}_{2}$ bath facilitated the formation of cylindrical fibers and led to the immediate solidification of the microfiber. The non-cross-linked $\mathrm{HA}$ dissolved in the bath, resulting in the central hollow structure. Subsequent UV cross-linking further enhanced the mechanical strength of the fibers. Via this approach, the continuous fabrication of $>1$-m-long microfibers was achieved under a variety of flow rates (e.g., from the innermost to the outermost, HA-ALG1-ALG2-DIW = 5-15-20-2 $\mu \mathrm{L}$ $\mathrm{min}^{-1}$; Figure $3 \mathrm{~A}-\mathrm{C}$ and Supporting Information, Video S1). In the bath solution, typical fibers had a smooth surface and a uniform diameter of $\sim 450 \mu \mathrm{m}$ (Figure 3C). This diameter of the hydrogel microfibers is expected because all presolidification samples flow into the $\mathrm{CaCl}_{2}$ solution through a uniform output tube; this is due to the quick curing process of alginate fluids.

The high strength of the microfibers supports the assembly into higher-ordered, larger constructs by various means. To demonstrate this, we manually wrapped a single fiber into tightly aligned bundles using a cylindrical stick as the collector, which was placed in a direction orthogonal to the microfiber, and a circle pattern with tweezers (Figure 3D,E) or tied several fibers into different shapes, such as a knot (Figure 3F), a braided pleat (Figure 3G), and a warp (Figure 3H), with tweezers. Finally, we integrated the chip with a $3 \mathrm{D}$ printer to demonstrate the automated assembly of fibers into customized shapes. As shown in Supporting Information, Video 2, continuously extruded microfibers were solidified in situ and simultaneously assembled layer-by-layer via the computercontrolled movement of the 3D printer head. A highly ordered, $3 \mathrm{~cm} \times 3 \mathrm{~cm}$ construct was produced (Figure 3I). These examples clearly illustrated the capability of this approach for the assembly of hierarchically microstructured building blocks, an approach that has great potential to generate large, complex tissues such as a blood network for vascularization.

2.3. Controlling the Structure of Hollow DoubleLayered Microfibers. The diffusion-driven transport of oxygen and nutrients in an engineered tissue is limited beyond $200-250 \mu \mathrm{m}$ from the surface. ${ }^{39}$ Therefore, a fiber containing a lumen that can aid mass transport will be a major advantage for cell growth and proliferation. A typical hollow microfiber is shown in Figure 4A, where the central hollow region is clearly seen in parts I-III. The lumen can easily be used as a conduit, as illustrated by a continuous flow of fluorescence beads within it (Supporting Information, Video S3). Both the internal and external diameters are uniform along the fiber, indicating the stable structure of a multiphased microfiber prior to solidification (Figure 4A, III). Without the use of a HA solution,
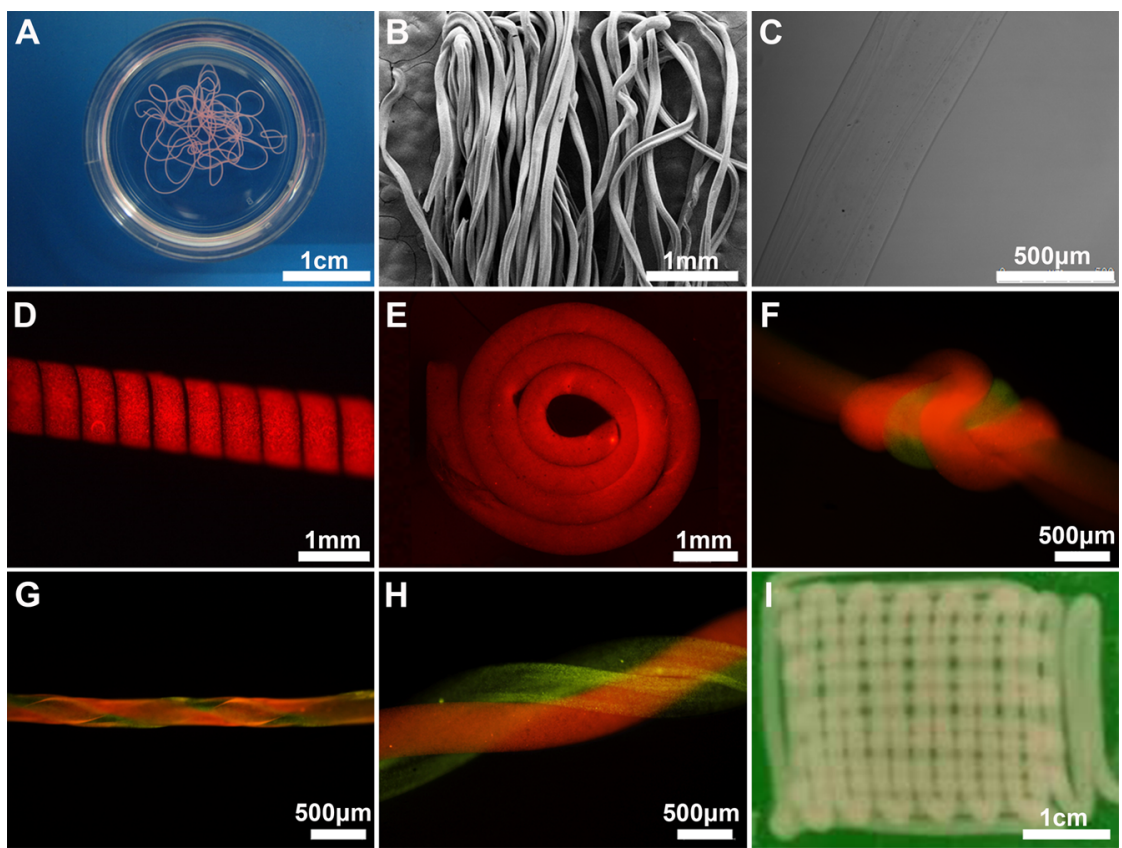

Figure 3. (A) Photograph of the ALG hydrogel microfibers with red fluorescence beads. (B) SEM image of microfibers. The distortion in the diameter of the fibers (compared to the wet conditions in part $\mathrm{C}$ ) is due to freeze-drying. (C) Bright-field image of a single alginate hydrogel microfiber in the bath solution. Fluorescence images of manually assembled constructs. (D and E) Tightly aligned fiber bundles and a circle pattern from a single fiber. (F and G) A microknot and a braid of two fibers. (H) A warp of three fibers. (I) Photograph of a large construct made by the automated assembly of in situ formed microfibers using $3 \mathrm{D}$ printing. 
(A)

(l)

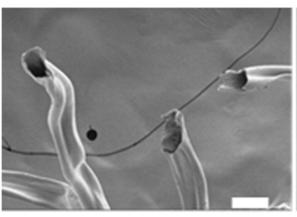

(B)

(I)

(II)

(III)
(II)

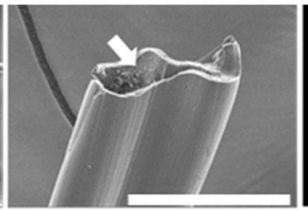

(III)

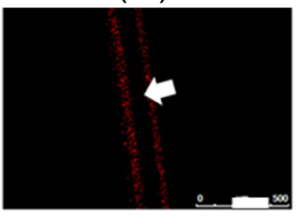

Bright Field

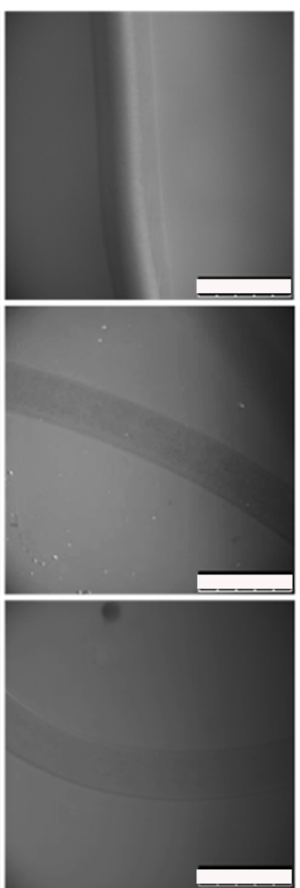

(IV)

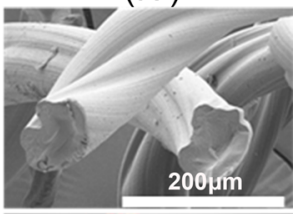

Merge

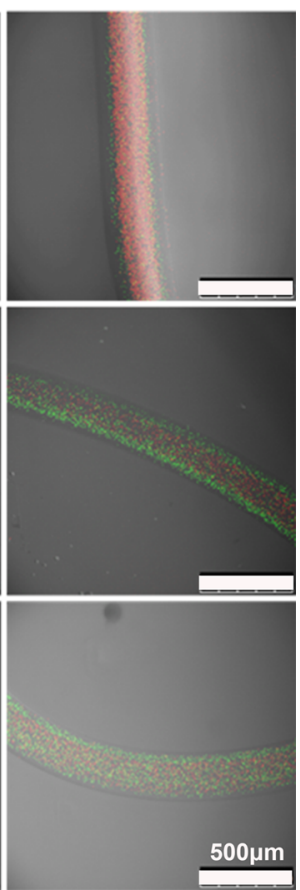

Figure 4. (A) Images of a typical hollow fiber. SEM images of the cross section at (I) low and (II) high magnifications. (III) Single section of the confocal fluorescence images. (IV) Optical image of the solid fiber. (B) Representative fluorescence and bright-field images of multilayered hydrogels formed at different flow rates for solutions of HA-ALG1-ALG2-DIW: (I) 5-5-20-2; (II) 5-15-20-2; (III) $10-15-20-2 \mu \mathrm{L} \mathrm{min}^{-1}$. Pseudocolors, red and green, represent red and green fluorescence beads, respectively. The HA layer contained red fluorescence beads. The ALG1 solution layer contained green fluorescence beads. The ALG2 layer did not contain any beads.

solid fibers were also obtained (Figure 4A, IV, and Supporting Information, Figure S2).

To optimize the thickness of the individual layers in the microfibers, flow rates for each solution were evaluated because the distribution of each solution in the cross section of the microchannel can be determined by their input flow rates. To aid visualization, red and green fluorescence beads were added to the HA and ALG1 solutions, respectively, whereas no beads were added to the ALG2 solution. The merged optical images of a microfiber showed the inner hollow structure (red), the middle green layer, and the outer transparent solid layer (Figure 4B). When the flow rate for one solution is changed, the dimensions of the hollow structure and each layer are varied (Figure 4B, I-III), thus offering a simple means to control the dimensions of the hierarchical components of the structured fibers.

Various combinations of flow rates were tested, and the thickness of each layer at each condition was evaluated from the combined fluorescence and bright-field images. As schematically shown in Figure 5A, the thickness of the inner layer (i.e., ALG1 layer, IT) is calculated based on eq 1 and that of the outer layer (i.e., ALG2, OT) is based on eq 2.

$$
\begin{aligned}
& \mathrm{IT}=\frac{\mathrm{L} 2-\mathrm{L} 1}{2} \\
& \mathrm{OT}=\frac{\mathrm{L} 3-\mathrm{L} 2}{2}
\end{aligned}
$$

where IT and OT are the thicknesses of the inner and outer layers, respectively. $\mathrm{L} 1$ is the width across the red fluorescence region, $\mathrm{L} 2$ is the length across the ends of the symmetric green fluorescence regions, and L3 is the length across the two ends of the bright-field regions.

At the fixed flow speed of $2 \mu \mathrm{L} \mathrm{min}{ }^{-1}$ for DIW, the flow speeds for the HA, ALG1, and ALG2 solutions were varied systematically (Figure 5B-D). Increasing the HA flow rates decreased both IT and OT, for example, from $48.44 \pm 4.83$ and $38.69 \pm 2.10 \mu \mathrm{m}$ at $2 \mu \mathrm{L} \mathrm{min}{ }^{-1}$ to $23.67 \pm 1.93$ and $25.78 \pm$ $0.92 \mu \mathrm{m}$ at $25 \mu \mathrm{L} \mathrm{min}{ }^{-1}$, respectively (Figure 5B). Similarly, an increase in the ALG1 flow rates led to an increase in IT but a decrease in OT (Figure 5C), and an increase in the ALG2 flow rates led to a decrease in IT but an increase in OT (Figure 5D). The fact that both IT and OT can be readily tuned with individual flow rates facilitates optimization of the dimension of each layer for targeted applications. 
A
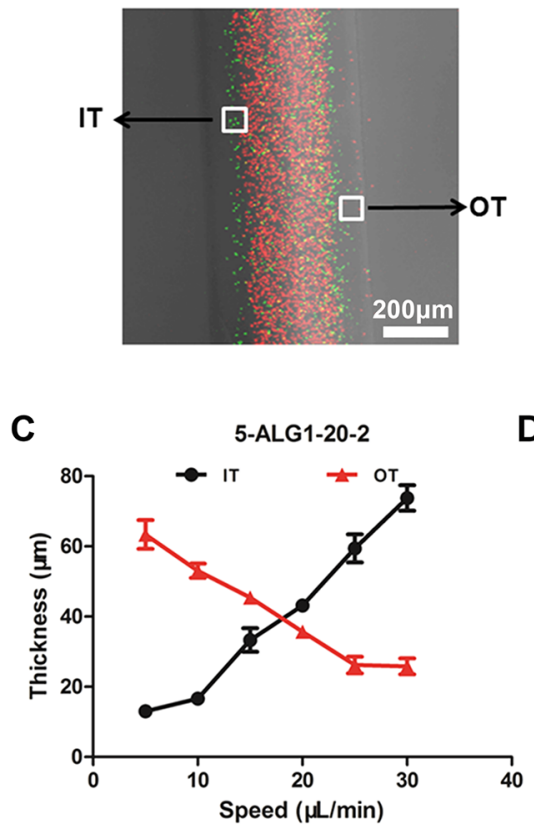

B

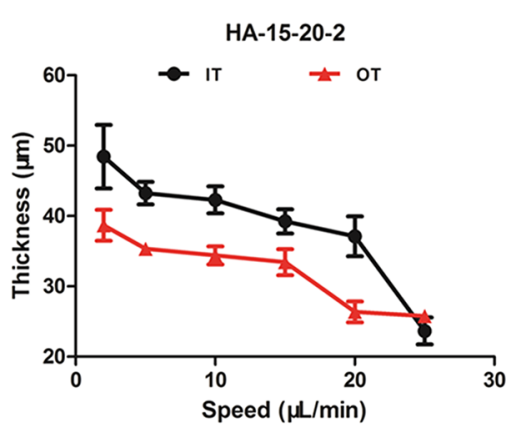

D

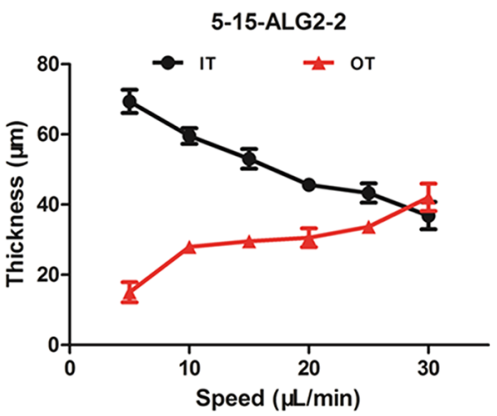

Figure 5. (A) Schematic illustrating the evaluation of IT (the thickness of the inner ALG1 layer) and OT (the thickness of the outer ALG2 layer). (B-D) Changes of the ITs and OTs with an increase in the flow rates of the HA, ALG1, and ALG2 solutions, respectively $(*, p<0.05)$.

(A)

(B)
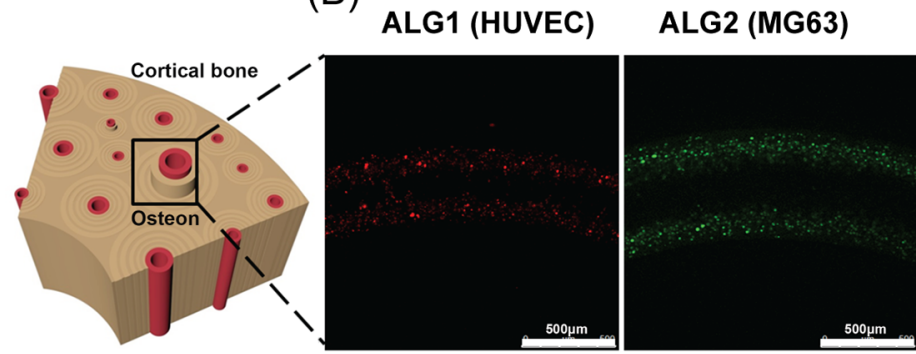

Bright field

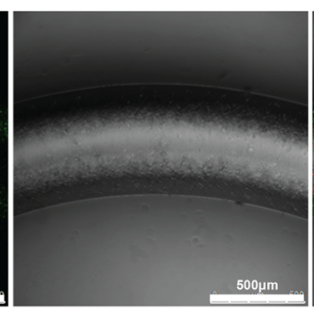

(D)
Merge

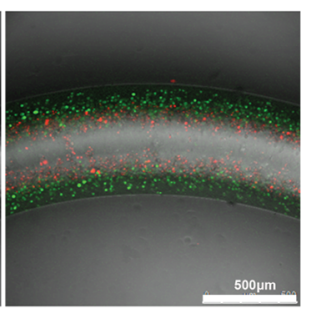

(E)

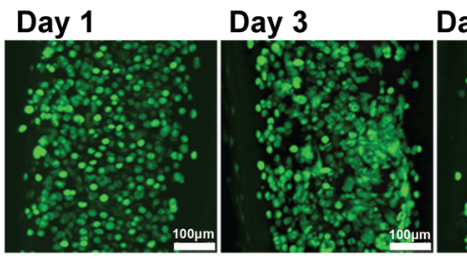

Day 5

Day 7

Day 10
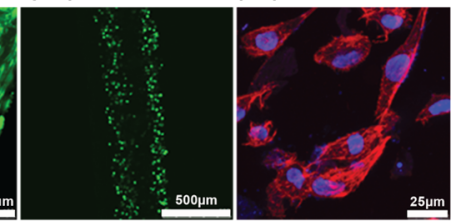

Figure 6. (A) Schematics showing the anatomical structure of osteons. (B) Representative fluorescence and bright-field images of the osteon-like microfibers. HUVECs (labeled with CM-DIL; pseudocolor, red) were encapsulated in the RGD-ALG1 layer and MG63 cells (labeled with CMFDA; pseudocolor, green) in the RGD-ALG2 layer. The fiber was fabricated at flow rates of 5-15-20-2 $\mu \mathrm{L} \mathrm{min}^{-1}$. (C) Fluorescent images of FDA/PI-stained HUVECs and MG63 cells within the osteon-like microfibers during the course of culture. (D) Confocal image (a single scan) from the middle of an osteon-like fiber. (E) DAPI (nuclei staining; pseudocolor, blue) and F-actin staining (pseudocolor, green) of an osteon-like fiber after 5 days in a culture.

2.4. Fabrication of Osteon-Like Microfibers. Hollow double-layered microfibers with a thinner inner layer and a thicker outer layer mimicking the structure of osteons were fabricated. The flow rates of HA-ALG1-ALG2-DIW at 5-

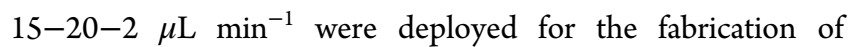
osteon-like fibers (Figure 5). Cortical bone is a highly vascularized tissue with precise yet complex organization of different cell populations. ${ }^{40}$ Anatomically, the basic unit of bone is the osteon, which consists of a core of tubular vasculature that is surrounded by several concentric lamellae of osteocytes (Figure 6A). ${ }^{41-43}$ Such a structure was created by the spatial organization of osteocytes, which are precursors for bone formation, and HUVECs, which are precursors for vasculature formation, in the form of hollow double-layered microfibers. Both cell types interact with each other and promote the formation of vascularized bone tissues in a coculture. ${ }^{44,45}$ Here, by the inclusion of HUVECs and MG63 cells in ALG1 and ALG2 solutions, respectively, a hollow “osteon"-like microfiber was produced. HUVECs (labeled with red, CM-DIL) were uniformly distributed within the inner layer and MG63 cells (labeled with green, CMFDA) in the outer layer (Figure 6B). 
Table 3. Primer Sequences for Target Genes

\begin{tabular}{ll}
\multicolumn{1}{c}{ gene } & \multicolumn{1}{c}{ forward primer } \\
ALP & TTGACCTCCTCGGAAGACACTC \\
BMP-2 & TTACTGCCACGGAGAATGCC \\
OCN & GAGGG CAGCGAGGTAGTGAA \\
Cfba-1 & CTCTACTATGGCACTTCGTCAG \\
CoL-1 & CACACGTCTCGGTCATGGTA \\
TIE2 & TGCCCAGATATTGGTGTCCT \\
VECAD & CTCTGCATCCTCACCATCAC \\
CD31 & ACTGCACAGCCTTCAACAGA \\
CD34 & TCCAGAAACGGCCATTCAG \\
VWF & GTCGAGCTGCACAGTGACAT \\
GAPDH & GCCAAGGCTGTGGGCAAGGT
\end{tabular}

reverse primer
CGCCTGGTAGTTGTTGTGAGC
CCCACAACCCTCCACAACCA
CCTCCTGAAAGCCGATGTGGT
GCTTCCATCAGCGTCAACAC
AAGAGGAAGGCCAAGTCGAG
CTCATAAAGCGTGGTATTCACGTA
GAGTTGAGCACCGACACATC
TTTCTTCCATGGGGCAAG
CCCCACCTAGCCGAGTCA
CCACGTAAGGAACAGAGACCA
AGGTGGAGGAGTGGGTGTCG

2.5. Functional Characterization of the Osteon-Like Microfibers. 2.5.1. Cell Spreading and Viability. Cell adhesion and spreading determine the proliferation, differentiation, and many other cell functions for anchoragedependent cells, such as osteocytes and HUVECs. The elongated cell morphology in 3D microenvironments relies on interactions between the cells and surrounding materials. However, pristine alginate lacks cell-adhesive sites. To overcome this limitation, RGD peptides were grafted onto ALG during fiber formation, giving rise to cell-laden RGD-ALG microfibers. To evaluate the effect of this grafting process, the cell morphology and proliferation within the microfibers were monitored for 10 days of culture. As illustrated in Figure 6C, the majority of the cells in the RGD-ALG microfibers were viable although rounded on day 1 , indicating that the fabrication process did not have detrimental effects on the cell viability. After 3 days in a culture, the majority of the cells were still viable and began to elongate, spread, and form direct cell-cell contact networks. After 5 days in a culture, a fully developed cell cytoskeleton with well-organized F-actin stress fibers was clearly observed (Figure 6C). In addition, there was an obvious increase in the number of spreading cells, and some cells began to form interconnected networks with neighboring cells (Supporting Information, Figure S3). These phenomena suggest that the introduction of cell-adhesive RGD peptides enhances cell attachment and proliferation. Meanwhile, the middle lumen structure (Figure 6D) retains its integrity during the period of culture (Supporting Information, Figure S4) and can be used for delivering nutrients or additional stimuli such as shear stress. It should be noted that, by a simple modification of the geometry of the microfluidic chips, more complex structures such as greater than three layers of different types of cells in a single fiber can be achieved. This will offer a powerful platform for applications that require well-defined spatial distribution and cocultures of different cell types.

2.5.2. Reverse-Transcription Polymerase Chain Reaction $(R T-P C R)$ and Immunofluorescence Staining. Expression of osteogenic genes by MG63 cells and vasculogenic genes by HUVECs in osteon-like fibers (denoted as $\mathrm{MH}$ ) was assessed by quantitative RT-PCR. The sequences of primers for different genes are given in Table 3. ALP, BMP-2, COL-1, Cbfal, and $\mathrm{OCN}$ were chosen as osteogenic makers (Figure 7A), whereas CD34, CD31, VECAD, TIE-2, and VWF (Figure 7B) were chosen as vasculogenic makers. Fibers with only MG63 cells in the RGD-ALG2 layer (M) and fibers with only HUVECs in the RGD-ALG1 layer (H) were taken as controls.

For ALP expression, the highest expression in both $\mathrm{MH}$ and $\mathrm{M}$ occurred at week 2 , and then the expression decreased to a lower level at week 3. This may indicate the preparation of the matrix for mineralization because the expression of ALP increases before mineralization and decreases after the start of mineralization. ${ }^{46}$ The BMP-2 expression showed a trend similar to that of ALP. Again, BMP-2 is typically upregulated at an early stage and then downregulated as mineralization progresses. $^{46}$ A significantly higher COL-1 expression was observed in $\mathrm{MH}$ at both weeks 2 and $3(*, p<0.05)$, indicating the active production of a native bone matrix of cells in $\mathrm{MH}$. Although there was no significant difference in the levels of OCN and Cbfal expression between two samples at weeks 1 and 2, significantly higher expression of both markers was observed in $\mathrm{MH}$ after 3 weeks in a culture. Cbfal is a specific transcriptional factor for regulating osteogenic gene expression and promoting bone formation. ${ }^{47}$ OCN regulates maturation into osteoblast lineage and is often used as a marker for latestage osteogenesis. ${ }^{48}$ The significantly increased levels of OCN, Cbfa-1, and COL-1 expression in $\mathrm{MH}$ fibers after 3 weeks consistently indicate that the biomimetic coculture of HUVECs and MG63 cells in the osteon-like fibers enhanced the osteogenic activity of the MG63 cells.

CD34, CD31, VECAD, TIE-2, and VWF are makers of vasculogenic differentiation. As a marker for early vasculogenic, CD34 expression induced expression of VECAD, CD31, and TIE2 in a later stage $e^{49-51}$ and was seen to decrease gradually with the maturation of cells. ${ }^{52}$ CD34 expression in $\mathrm{MH}$ was significantly higher than that in $\mathrm{H}$ at week $2(*, p<0.05)$, and expression for both fibers decreased at week 3, which may indicate cell maturation. The expression levels of CD31, VECAD, TIE-2, and VWF in both $\mathrm{MH}$ and $\mathrm{H}$ increased with the time in a culture. However, the expressions of all of these markers except CD31 were significantly higher than that of control $\mathrm{H}$ after week 2 (i.e., weeks 2 and 3 ). Significantly higher $\mathrm{CD} 31$ expression was observed in $\mathrm{MH}$ only after 3 weeks in a culture. All of the variations in the expression levels agree well with each other and clearly demonstrate significantly upregulated vasculogenic expression of HUVECs in MH. In summary, substantially higher expression of phenotypical genes in $\mathrm{MH}$ microfibers occurred, demonstrating that a biomimetic coculture of different cells promotes expression of the osteogenic and vasculogenic genes.

Immunofluorescence staining of osetogenic (OCN and COL-1) and vasculogenic (VWF and VECAD) markers was further employed to characterize the phenotypic functions of cells in the fibers. Substantial production of the four markers was observed after 5 days in $\mathrm{MH}$ (Figure 8A,B). In contrast, negative staining was found in both controls ( $M$ and $H$ ). Furthermore, the intense VECAD immunofluorescence signal 
A

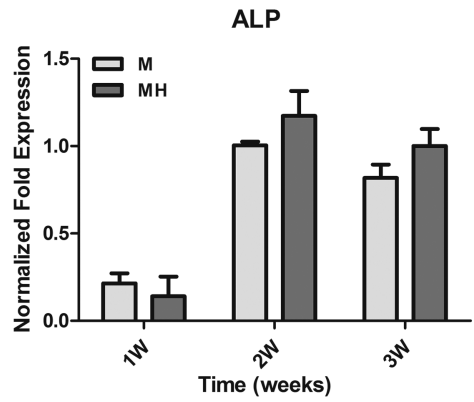

COL-1

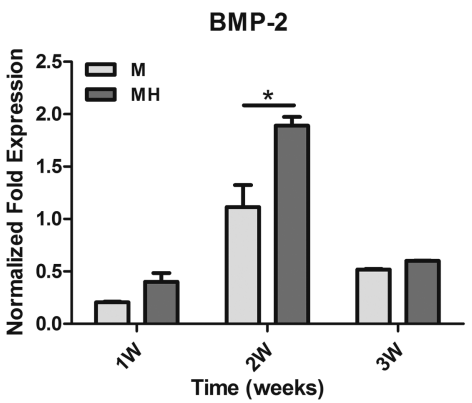

Cbfa1
OCN
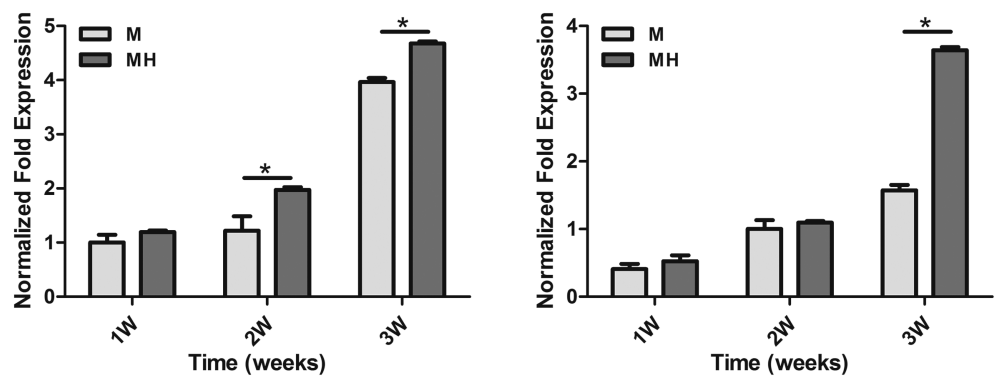
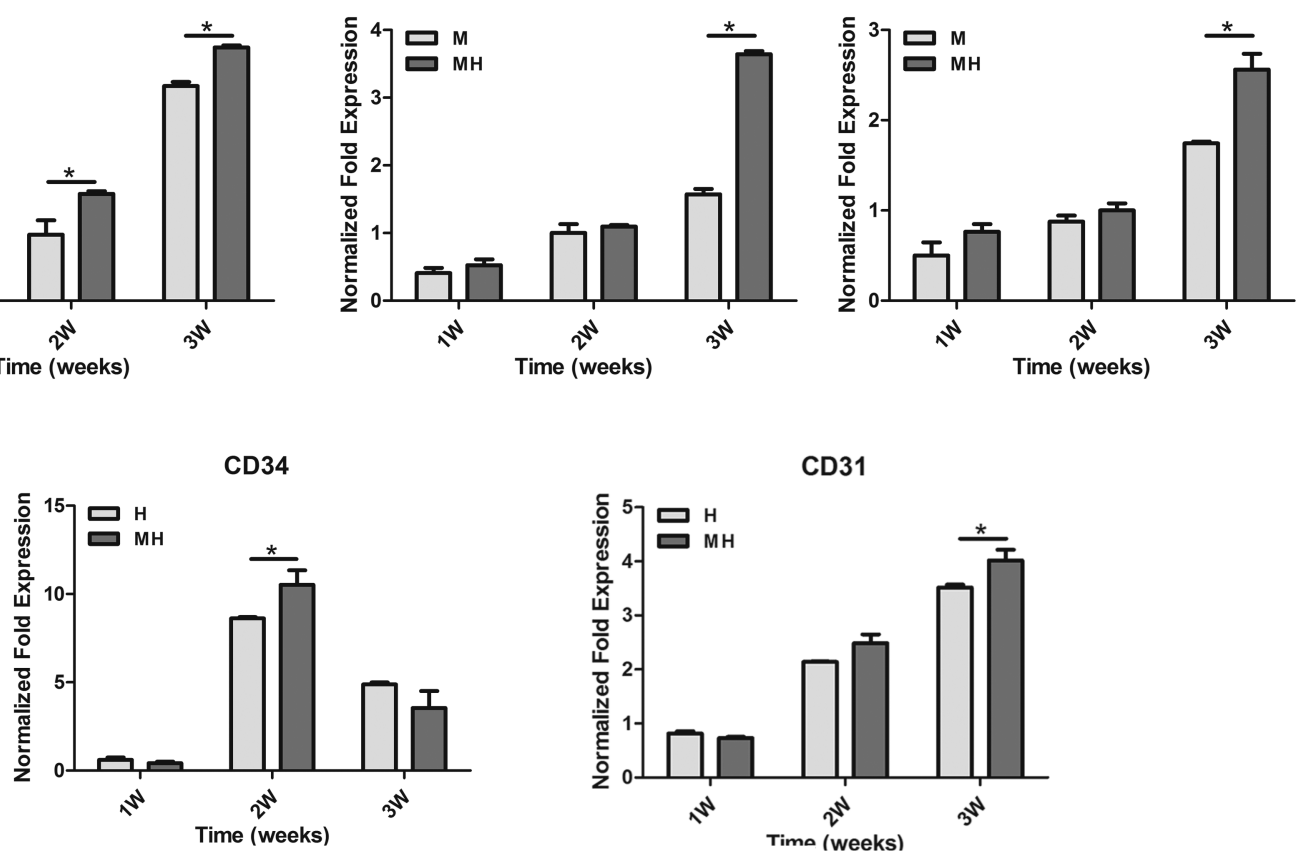

VECAD

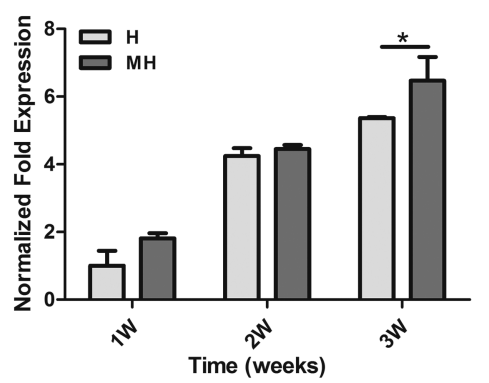

CD31

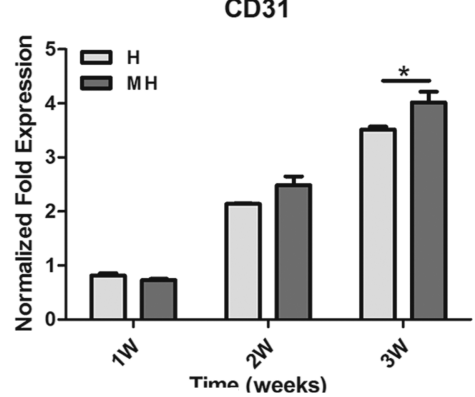

TIE2

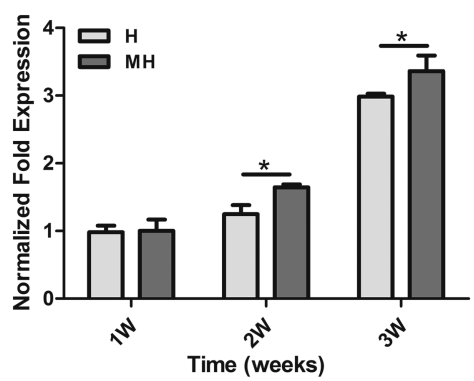

VWF

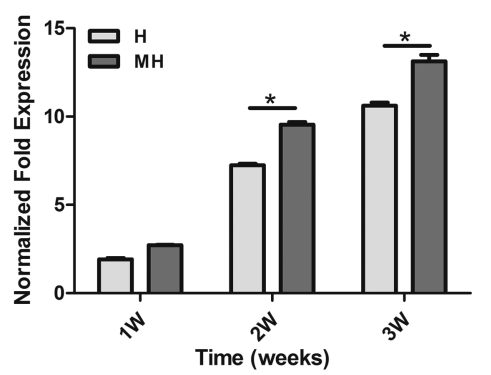

Figure 7. Quantitative gene expressions of MG63 cells and HUVECs in various hydrogel microfibers at the end of weeks 1-3. (A) Expression of genes relevant to osteogenic makers. (B) Expression of genes relevant to vasculogenic makers.

was mainly distributed between the boundaries of the cells, indicating the formation of adherens junctions. These observations further confirm that biomimetic osteon-like microfibers contain significant vasculogenic and osteogenic activities.

\section{CONCLUSIONS}

A facile method has been developed for the continuous fabrication of a variety of functional cell-laden microfibers that can be easily assembled into large tissue constructs. The method employs easy-to-fabricate microfluidic chips to control cells precisely at the microscale. This enables the creation of multilayered fibers of different shapes (i.e., solid or hollow), internal structures, dimensions, and compositions (i.e., cells or other biomolecules) from a single platform. The combination of both ionic and UV cross-linking for methacrylated alginate allows a continuous fabrication process and the creation of bioactive ECM with tunable physiochemical and biological properties. The grafting of RGD peptides into the microfiber facilitated cell spreading and proliferation.

Importantly, the innovative integration of microfluidics and functional biomaterials significantly enhanced our capability of creating large functional tissues of complex structure. Meterlong, hollow, osteon-like microfibers with precisely controlled organization of HUVECs and MG63 cells were produced that successfully demonstrate enhanced vasculogenic and osteogenic 
A

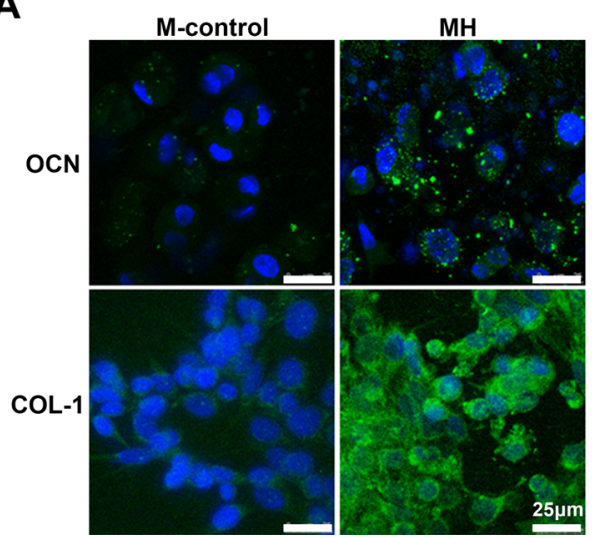

B

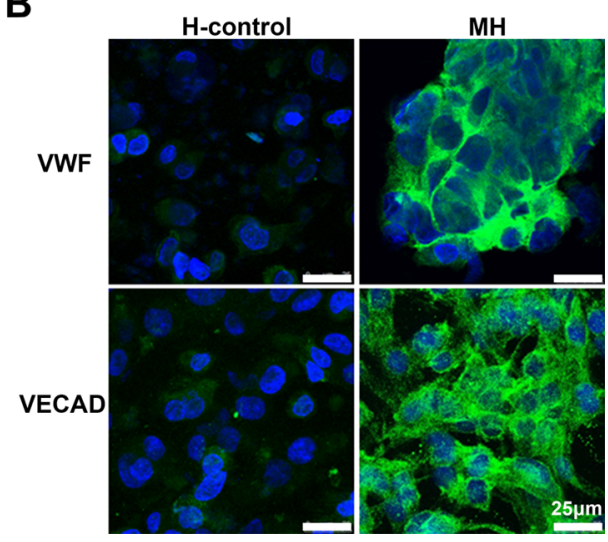

Figure 8. Immunoflurescence images from the osteon-like fiber (MH). (A) OCN and COL-1 staining of the M and MH fibers, respectively. (B) VWF and VECAD staining of the M and MH fibers, respectively. Pseudocolors: green, staining; blue, nuclei staining.

expression. Because of the simplicity and reliability of chip fabrication, it is expected that more complex structures such as those with greater than four multilayers, which are difficult to produce with the current methods, can be readily created via this approach. Combining this continuous fabrication with 3D printing provides great potential for regenerating large tissues of complex anatomical structures.

\section{EXPERIMENTAL SECTION}

4.1. Materials. Sodium alginate was purchased from Wako (Osaka, Japan). Sodium hyaluronate $(\mathrm{HA} ; \mathrm{MW}=300000 \mathrm{Da})$ was purchased from Bloomage Freda Biopharm Co., Ltd. (China). Cell-adhesive peptide (GCGYGRGDSPG; MW $=1025.1 \mathrm{Da}$ ) with $>95 \%$ purity was obtained from China Peptides Co., Ltd. Fluorescent microparticles were purchased from Invitrogen (USA). Methacrylic anhydride, photoinitiator \{2-hydroxy-1-[4-(hydroxyethoxy)phenyl]-2 methyl-1propanone (Irgacure 2959)\}, phalloidin, 4',6-diamidino-2-phenylindole (DAPI), fluorescein diacetate (FDA), and propidium iodide (PI) were purchased from Sigma-Aldrich (USA). All other chemicals were from Chengdu Kelong Chem Co. Syringe pumps were purchased from Lange Baoding Co. Ltd. (Hebei, China). The UV-light source (OmnicureS1500) was purchased from EXFO Photonic Solutions Inc. (Ontario, Canada). A simple 3D printer was purchased from Beijing Oubang Chem Co.

4.2. Fabrication of a Microfluidic Device Based on PDMS. The microfluidic chips were made by casting a PDMS elastomer against a silicon master as described previously. ${ }^{53}$ The silicon master for the devices was manufactured using standard lithography techniques with a Microchem SU8-2005 resist. The width of all of the side channels was $100 \mu \mathrm{m}$, and the width of the middle, main channel was $300 \mu \mathrm{m}$. The depth for all channels was $135 \mu \mathrm{m}$. After treatment of the mold with trichloro $(1 \mathrm{H}, 1 \mathrm{H}, 2 \mathrm{H}, 2 \mathrm{H}$-perfluorooctyl)silane in a desiccator under vacuum, Sylgard 184 PDMS mixed in a ratio of 10:1 elastomer/curing agent was poured onto it and then cured in an oven. The cured device was peeled from the mold, connection holes were punched, and then the device was bonded to a glass microscope slide following treatment in oxygen plasma.

4.3. Methacrylated Alginate (ALG) Synthesis. ALG was synthesized as described before. ${ }^{43}$ Briefly, alginate powder $(1 \mathrm{~g})$ was dissolved in a $100 \mathrm{~mL}$ PBS solution at $4{ }^{\circ} \mathrm{C}$. The acrylation reaction took place under stirring for $48 \mathrm{~h}$ after the addition of $15 \mathrm{~mL}$ of methacrylic anhydride. The $\mathrm{pH}$ of the mixture was adjusted to 8 periodically using $0.5 \mathrm{M} \mathrm{NaOH}$. The modified alginate was purified via dialysis in DIW for 7 days at $4{ }^{\circ} \mathrm{C}$, and the final product was recovered by lyophilization. The methacrylation percentage of ALG used in these experiments was roughly $45 \% .{ }^{43}$

4.4. Fabrication of Bulk Hydrogels. The hydrogel precursors were dissolved in a triethanolamine-buffered saline (TEOA buffer: 0.2 $\mathrm{M}$ TEOA, $0.3 \mathrm{M}$ total osmolarity, $\mathrm{pH} 8.0)$ with a $0.5 \%(\mathrm{w} / \mathrm{v})$ photoinitiator (12959). The hydrogel prepolymers were formed and named (Table 1). Then the solutions were vibrated for $1 \mathrm{~h}$ to obtain a homogeneous mixture. The mixed solution was transferred into a cylindrical PDMS mold (diameter $=8 \mathrm{~mm}$; height $=2.0 \mathrm{~mm}$ ) with a pipet and then exposed to $8.0 \mathrm{~mW} \mathrm{~cm} \mathrm{~cm}^{-2}$ UV light $(360-480 \mathrm{~nm})$ for $20 \mathrm{~s}$.

4.5. Mechanical Test. The compressive moduli of the several hydrogels were characterized at an amplitude of $20 \mathrm{~mm}$ with $5 \mathrm{mN}$ prestress using a dynamic mechanical analyzer (TA Q-800). Five parallel samples per group were tested, and all of the data were averaged.

4.6. Generation of Hollow Double-Layered Microfibers. To generate hollow double-layered microfibers, we prepared a $1.5 \%(\mathrm{w} / \mathrm{v})$ solution of ALG in DIW with 0.5\% I2959. A 2\% HA solution was used for the lumen solution. ALG1, ALG2, HA, and DIW solutions were fed into four syringes. Each syringe was attached to an injection pump through a Teflon microtube with $300 \mu \mathrm{m}$ inner diameter and $500 \mu \mathrm{m}$ external diameter. Injection rates varied between 0 and $50 \mu \mathrm{L} \mathrm{min}^{-1}$. The resulting microfibers were harvested in $\mathrm{CaCl}_{2}(300 \mathrm{mM})$, then transferred to a dish, and subjected to $10 \mathrm{~s}$ of UV irradiation at $8 \mathrm{~mW}$ $\mathrm{cm}^{-2}$. Uncured HA solution easily flowed out of the lumen in a short time. The viscosities of different solutions used in the experiment are shown in Table 2.

4.7. Morphology Characterization of Hollow DoubleLayered Microfibers. An optical microscope (Leica 4000) was employed to study the surface morphology and size of the hydrogel fibers. Fluorescence beads were added at a volume ratio of $0.2 \%$ to the solutions to aid visualization. Scanning electron microscopy (SEM) images of the microfibers were obtained using a field-emission scanning electron microscope (S-4800, Hitachi, Japan) at an acceleration voltage of $3.0 \mathrm{kV}$.

4.8. Assembly of the Microfibers into Larger Constructs. We wrapped a single fiber onto a needle using tweezers for the tightly aligned bundles and a circle pattern. Multiple fibers were also manually assembled into various shapes. The automated and continuous assembly of microfibers was achieved by fixing the Teflon tubing onto the moving head of a $3 \mathrm{D}$ printer and immersing the tubing in the $\mathrm{CaCl}_{2}$ bath so that the extruded liquid phase could solidify immediately in situ. The speed of the moving head was $16 \mathrm{~mm} \mathrm{~s}^{-1}$. The layer-by-layer assembly of microfibers was carried out to form a large construct.

4.9. Optimization of the Structure of Hollow DoubleLayered Microfibers. Red (excitation at $535 \mathrm{~nm}$ and emission at $575 \mathrm{~nm}$ ) and green (excitation at $495 \mathrm{~nm}$ and emission at $505 \mathrm{~nm}$ ) fluorescence beads $(0.2 \%, \mathrm{v} / \mathrm{v})$ were added in HA and ALG1 solutions separately. The hydrogel fibers were prepared as described above. To image the fibers, the two ends of a fiber were lifted out of the $\mathrm{CaCl}_{2}$ solution so that the internal HA solution mixed with red fluorescence beads could not flow. The fiber was then imaged using a confocal laser scanning microscope (Leica SP5, Leica Microsystems, Wetzlar, 
Germany). The fibers were immersed in a $0.9 \% \mathrm{NaCl}$ solution to maintain the cylindrical shape. The thickness of the individual layers in the fibers was evaluated using ImageJ from the confocal images. An average of five measurements was used as the size of a fiber. Five parallel samples per group were tested, and all of the data were averaged.

4.10. Cell Culture and Cell Encapsulation. Human osteoblastlike cells (MG63 cells) and human umbilical cord vein endothelial cells (HUVECs) were maintained in Dulbecco's modified Eagle's medium (Hyclone), supplemented with $10 \%$ fetal bovine serum and $1 \%$ penicillin/streptomycin. RGD in TEOA buffer was added to the ALG solution at a concentration that consumes $10 \%$ acrylate groups on ALG based on the Michael-type addition chemistry and allowed to react for $1 \mathrm{~h}$ at $37^{\circ} \mathrm{C}$. HUVECs and MG63 cells were mixed in the RGD-ALG1 and RGD-ALG2 precursors at a density of $1 \times 10^{7}$ cells/mL, respectively. Then cell-laden, hollow double-layered fibers were fabricated as described above. The fibers were solidified in 100 $\mathrm{mM} \mathrm{CaCl}_{2}$ and further UV-cross-linked at $8 \mathrm{~mW} \mathrm{~cm}^{-2}$ for $10 \mathrm{~s}$. Good cytocompatibility was expected with such mild exposure conditions. ${ }^{54,55}$ The whole fabrication process was performed under sterile conditions.

4.11. Cell Viability and Morphology. Cell-laden hydrogel fibers were stained with FDA/PI (i.e., live and dead assay) to investigate the proliferation, distribution, and morphology. For actin cytoskeleton staining, the fibers were washed three times in $0.9 \% \mathrm{NaCl}$ and fixed in a $4 \%$ paraformaldehyde solution for $5 \mathrm{~min}$. After rinsing with a $0.9 \%$ $\mathrm{NaCl}$ solution, $50 \mathrm{mg} \mathrm{mL}^{-1}$ phalloidin was added to stain the actin cytoskeleton, following $45 \mathrm{~min}$ of incubation at room temperature. The samples were then rinsed and incubated in a $0.1 \%(\mathrm{v} / \mathrm{v})$ DAPI solution for $1 \mathrm{~min}$ to stain the nuclei for confocal imaging.

MTT assay was used to investigate the cell viability, while MG63 cells were encapsulated in bulk ALG and RGD-ALG hydrogels. Cells encapsulated in samples gelled using $50 \mu \mathrm{L}$ prepolymer solutions were incubated with $0.5 \mathrm{mg} \mathrm{mL} \mathrm{m}^{-1} \mathrm{MTT}$ for $4 \mathrm{~h}$ at $37^{\circ} \mathrm{C}$ in the dark. Then the MTT solution was removed, and purple formazan salts dissolved with dimethyl sulfoxide. Finally, the absorbance of the resulting solution was measured at $490 \mathrm{~nm}$ using a multidetection microplate reader (Bio-Rad 550). Five parallel hydrogel samples per group were tested, and all of the data were averaged.

4.12. Gene Expression. Gene expression associated with osteogenesis and vasculogenesis included osteocalcin $(\mathrm{OCN})$, platelet endothelial cell adhesion molecule-31 (CD31), hematopoietic progenitor cell antigen (CD34), tyrosine kinase with immunoglobulin-like and EGF-like domains 2 (TIE-2), VE-cadherin (VECAD), von Willebrand factor (VWF), alkaline phosphatase (ALP), bone morphogenetic protein-2 (BMP-2), core binding factor a1 (Cbfa1), and collagen type I (COL-1). All gene expressions were assessed by RT-PCR. After culture for 7, 14, and 21 days, total RNA was isolated from cells using a Trizol reagent (Invitrogen). RNA extracted from differentiated cells were converted into complementary DNA (cDNA) using the RT-PCR Kit (Toyobo, Osaka, Japan) according to the manufacturer's instructions. Quantitative real-time RT-PCR was performed by a FTC-2000 RealTime Fluorescence Quantitative Thermocycler (FungLyn Biotech Corp. Ltd., Shanghai, China). Primers used for amplification are listed in Table 3.

4.13. Immunostaining. Specific protein markers associated with osteogenesis and vasculogenesis, including OCN, COL-1, VWF, and VECAD, were analyzed by immunostaining. The cell-laden hydrogel fibers were washed in a $0.9 \% \mathrm{NaCl}$ solution and fixed in ice acetone for $15 \mathrm{~min}$. Prior to each step, samples were rinsed three times in a $0.9 \%$ $\mathrm{NaCl}$ solution unless denoted otherwise. First, Triton X-100 (0.2\%, v/ v) was added to the samples for $5 \mathrm{~min}$ for cell permeabilization. This was followed by the blocking of nonspecific adsorption using goat serum for $30 \mathrm{~min}$ at room temperature, then incubation with the primary antibody solution at $4{ }^{\circ} \mathrm{C}$ overnight, and incubation with the second antibody solution for $1 \mathrm{~h}$ at room temperature in the dark. Finally, the fibers were incubated in a DAPI solution for $5 \mathrm{~min}$ to stain the nuclei, after which the fibers were washed for confocal imaging.

4.14. Statistical Analysis. All of the experimental data are presented as mean \pm standard deviation. A paired Student's $t$ test was used to test for statistical significance between two types of samples. Significance levels were determined by $(*) p<0.05$.

\section{ASSOCIATED CONTENT}

\section{Supporting Information}

The Supporting Information is available free of charge on the ACS Publications website at DOI: 10.1021/acsami.7b00078.

FDA/PI staining images of MG63 cells encapsulated in various hydrogels and SEM images of the cross section of a solid fiber, cell-cell contacts, and lumen maintenance (PDF)

Fabrication process of microfibers (AVI)

Automated assembly of microfibers (AVI)

Microbeads flowing in the lumen part (AVI)

\section{AUTHOR INFORMATION}

\section{Corresponding Authors}

*E-mail: huabing.yin@glasgow.ac.uk.

*E-mail: hsfan@scu.edu.cn.

ORCID

Dan Wei: 0000-0003-4869-8615

Hongsong Fan: 0000-0003-3812-9208

\section{Author Contributions}

†These authors contributed equally to this work.

Notes

The authors declare no competing financial interest.

\section{ACKNOWLEDGMENTS}

This work was supported by the National Natural Science Foundation of China (Grants 51473098 and 51673128). We are also thankful for support from the EPSRC (EP/J009121/1) and BBSRC (BB/J021083/1).

\section{REFERENCES}

(1) Lutolf, M.; Hubbell, J. Synthetic Biomaterials as Instructive Extracellular Microenvironments for Morphogenesis in Tissue Engineering. Nat. Biotechnol. 2005, 23, 47-55.

(2) Slaughter, B. V.; Khurshid, S. S.; Fisher, O. Z.; Khademhosseini, A.; Peppas, N. A. Hydrogels in Regenerative Medicine. Adv. Mater. 2009, 21, 3307-3329.

(3) Liu Tsang, V.; Bhatia, S. N. Three-Dimensional Tissue Fabrication. Adv. Drug Delivery Rev. 2004, 56, 1635-1647.

(4) Bartold, P.; Mcculloch, C. A.; Narayanan, A. S.; Pitaru, S. Tissue Engineering: A New Paradigm for Periodontal Regeneration Based on Molecular and Cell Biology. Periodontol. 2000, 24, 253-269.

(5) Matsunaga, Y. T.; Morimoto, Y.; Takeuchi, S. Molding Cell Beads for Rapid Construction of Macroscopic 3D Tissue Architecture. Adv. Mater. 2011, 23, H90-94.

(6) Griffith, L. G.; Swartz, M. A. Capturing Complex 3D Tissue Physiology in Vitro. Nat. Rev. Mol. Cell Biol. 2006, 7, 211-224.

(7) Khademhosseini, A.; Langer, R.; Borenstein, J.; Vacanti, J. P. Microscale Technologies for Tissue Engineering and Biology. Proc. Natl. Acad. Sci. U. S. A. 2006, 103, 2480-2487.

(8) Bhatia, S. N.; Yarmush, M. L.; Toner, M. Controlling Cell Interactions by Micropatterning in Co-Cultures: Hepatocytes and 3T3 Fibroblasts. J. Biomed. Mater. Res. 1997, 34, 189-199.

(9) Singhvi, R.; Kumar, A.; Lopez, G. P.; Stephanopoulos, G. N.; Wang, D.; Whitesides, G. M.; Ingber, D. E. Engineering Cell Shape and Function. Science 1994, 264, 696-698.

(10) Hoffmann, J. C.; West, J. L. Three-Dimensional Photolithographic Patterning of Multiple Bioactive Ligands in Poly (ethylene glycol) Hydrogels. Soft Matter 2010, 6, 5056-5063.

(11) Jeong, W. J.; Kim, J. Y.; Choo, J.; Lee, E. K.; Han, C. S.; Beebe, D. J.; Seong, G. H.; Lee, S. H. Continuous Fabrication of Biocatalyst 
Immobilized Microparticles Using Photopolymerization and Immiscible Liquids in Microfluidic Systems. Langmuir 2005, 21, 3738-3741. (12) Du, Y.; Lo, E.; Ali, S.; Khademhosseini, A. Directed Assembly of Cell-laden Microgels for Fabrication of 3D Tissue Constructs. Proc. Natl. Acad. Sci. U. S. A. 2008, 105, 9522-9527.

(13) Davey, S. K.; Aung, A.; Agrawal, G.; Lim, H. L.; Kar, M.; Varghese, S. Embedded 3D Photopatterning of Hydrogels with Diverse and Complex Architectures for Tissue Engineering and Disease Models. Tissue Eng., Part C 2015, 21, 1188-1196.

(14) Tsang, V. L.; Chen, A. A.; Cho, L. M.; Jadin, K. D.; Sah, R. L.; DeLong, S.; West, J. L.; Bhatia, S. N. Fabrication of 3D Hepatic Tissues by Additive Photopatterning of Cellular Hydrogels. FASEB J. 2007, 21, 790-801.

(15) Beebe, D. J.; Moore, J. S.; Bauer, J. M.; Yu, Q.; Liu, R. H.; Devadoss, C.; Jo, B.-H. Functional Hydrogel Structures for Autonomous Flow Control Inside Microfluidic Channels. Nature 2000, 404, 588-590.

(16) Yin, H.; Marshall, D. Microfluidics for Single Cell Analysis. Curr. Opin. Biotechnol. 2012, 23, 110-119.

(17) Shepherd, R. F.; Conrad, J. C.; Rhodes, S. K.; Link, D. R.; Marquez, M.; Weitz, D. A.; Lewis, J. A. Microfluidic Assembly of Homogeneous and Janus Colloid-Filled Hydrogel Granules. Langmuir 2006, 22, 8618-8622.

(18) Choi, C.-H.; Yi, H.; Hwang, S.; Weitz, D. A.; Lee, C.-S. Microfluidic Fabrication of Complex-Shaped Microfibers by Liquid Template-Aided Multiphase Microflow. Lab Chip 2011, 11, 14771483.

(19) Leng, L.; McAllister, A.; Zhang, B.; Radisic, M.; Günther, A. Mosaic Hydrogels: One-Step Formation of Multiscale Soft Materials. Adv. Mater. 2012, 24, 3650-3658.

(20) Kang, E.; Jeong, G. S.; Choi, Y. Y.; Lee, K. H.; Khademhosseini, A.; Lee, S.-H. Digitally Tunable Physicochemical Coding of Material Composition and Topography in Continuous Microfibres. Nat. Mater. 2011, 10, 877-883.

(21) Jun, Y.; Kang, E.; Chae, S.; Lee, S.-H. Microfluidic Spinning of Micro-and Nano-scale Fibers for Tissue Engineering. Lab Chip 2014, $14,2145-2160$.

(22) Onoe, H.; Takeuchi, S. Cell-Laden Microfibers for Bottom-Up Tissue Engineering. Drug Discovery Today 2015, 20, 236-246.

(23) Yamada, M.; Sugaya, S.; Naganuma, Y.; Seki, M. Microfluidic Synthesis of Chemically and Physically Anisotropic Hydrogel Microfibers for Guided Cell Growth and Networking. Soft Matter 2012, 8, $3122-3130$

(24) Kunze, A.; Bertsch, A.; Giugliano, M.; Renaud, P. Microfluidic Hydrogel Layers with Multiple Gradients to Stimulate and Perfuse Three-dimensional Neuronal Cell Cultures. Procedia Chem. 2009, 1, 369-372.

(25) Cheng, Y.; Yu, Y.; Fu, F.; Wang, J.; Shang, L.; Gu, Z.; Zhao, Y. Controlled Fabrication of Bioactive Microfibers for Creating Tissue Constructs Using Microfluidic Techniques. ACS Appl. Mater. Interfaces 2016, 8, 1080-1086.

(26) Shi, X.; Ostrovidov, S.; Zhao, Y.; Liang, X.; Kasuya, M.; Kurihara, K.; Nakajima, K.; Bae, H.; Wu, H.; Khademhosseini, A. Microfluidic Spinning of Cell-Responsive Grooved Microfibers. Adv. Funct. Mater. 2015, 25, 2250-2259.

(27) Onoe, H.; Okitsu, T.; Itou, A.; Kato-Negishi, M.; Gojo, R.; Kiriya, D.; Sato, K.; Miura, S.; Iwanaga, S.; Kuribayashi-Shigetomi, K.; Matsunaga, Y. T.; Shimoyama, Y.; Takeuchi, S. Metre-Long Cell-laden Microfibres Exhibit Tissue Morphologies and Functions. Nat. Mater. 2013, 12, 584-590.

(28) Lee, K. H.; Shin, S. J.; Park, Y.; Lee, S. H. Synthesis of CellLaden Alginate Hollow Fibers Using Microfluidic Chips and Microvascularized Tissue-Engineering Applications. Small 2009, 5, $1264-1268$.

(29) Zuo, Y.; He, X.; Yang, Y.; Wei, D.; Sun, J.; Zhong, M.; Xie, R.; Fan, H.; Zhang, X. Microfluidic-Based Generation of Functional Microfibers for Biomimetic Complex Tissue Construction. Acta Biomater. 2016, 38, 153-162.
(30) Shen, C.; Zhang, G.; Wang, Q.; Meng, Q. Fabrication of Collagen Gel Hollow Fibers by Covalent Cross-Linking for Construction of Bioengineering Renal Tubules. ACS Appl. Mater. Interfaces 2015, 7, 19789-19797.

(31) Shin, S.-J.; Park, J.-Y.; Lee, J.-Y.; Park, H.; Park, Y.-D.; Lee, K.-B.; Whang, C.-M.; Lee, S.-H. On The Fly" Continuous Generation of Alginate Fibers Using A Microfluidic Device. Langmuir 2007, 23, 9104-9108.

(32) Takei, T.; Kishihara, N.; Sakai, S.; Kawakami, K. Novel Technique to Control Inner and Outer Diameter of Calcium-Alginate Hydrogel Hollow Microfibers, and Immobilization of Mammalian Cells. Biochem. Eng. J. 2010, 49, 143-147.

(33) Lee, B. R.; Lee, K. H.; Kang, E.; Kim, D.-S.; Lee, S.-H. Microfluidic Wet Spinning of Chitosan-Alginate Microfibers and Encapsulation of HepG2 Cells in Fibers. Biomicrofluidics 2011, 5, 022208 .

(34) Drury, J. L.; Mooney, D. J. Hydrogels for Tissue Engineering: Scaffold Design Variables and Applications. Biomaterials 2003, 24, 4337-4351.

(35) Cheng, Y.; Zheng, F.; Lu, J.; Shang, L.; Xie, Z.; Zhao, Y.; Chen, Y.; Gu, Z. Bioinspired Multicompartmental Microfibers from Microfluidics. Adv. Mater. 2014, 26, 5184-5190.

(36) Jeon, O.; Powell, C.; Ahmed, S. M.; Alsberg, E. Biodegradable, Photocrosslinked Alginate Hydrogels With Independently Tailorable Physical Properties and Cell Adhesivity. Tissue Eng., Part A 2010, 16, 2915-2925

(37) Sun, J.; Wei, D.; Zhu, Y.; Zhong, M.; Zuo, Y.; Fan, H.; Zhang, X. A Spatial Patternable Macroporous Hydrogel with Cell-affinity Domains to Enhance Cell Spreading and Differentiation. Biomaterials 2014, 35, 4759-4768.

(38) Rowley, J. A.; Madlambayan, G.; Mooney, D. J. Alginate Hydrogels as Synthetic Extracellular Matrix materials. Biomaterials 1999, 20, 45-53.

(39) Fidkowski, C.; Kaazempur-Mofrad, M. R.; Borenstein, J.; Vacanti, J. P.; Langer, R.; Wang, Y. Endothelialized Microvasculature Based on a Biodegradable Elastomer. Tissue Eng. 2005, 11, 302-309.

(40) Rho, J.-Y.; Kuhn-Spearing, L.; Zioupos, P. Mechanical Properties and The Hierarchical Structure of Bone. Med. Eng. Phys. 1998, 20, 92-102.

(41) Hofmann, T.; Heyroth, F.; Meinhard, H.; Fränzel, W.; Raum, K. Assessment of Composition and Anisotropic Elastic Properties of Secondary Osteon Lamellae. J. Biomech. 2006, 39, 2282-2294.

(42) Chen, X.; Ergun, A.; Gevgilili, H.; Ozkan, S.; Kalyon, D. M.; Wang, H. Shell-Core Bi-Layered Scaffolds for Engineering of Vascularized Osteon-Like Structures. Biomaterials 2013, 34, 82038212.

(43) Wei, D.; Xiao, W.; Sun, J.; Zhong, M.; Guo, L.; Fan, H.; Zhang, $\mathrm{X}$. A Biocompatible Hydrogel with Improved Stiffness and Hydrophilicity for Modular Tissue Engineering Assembly. J. Mater. Chem. B 2015, 3, 2753-2763.

(44) Gu, Z.; Xie, H.; Li, L.; Zhang, X.; Liu, F.; Yu, X. Application of Strontium-Doped Calcium Polyphosphate Scaffold on Angiogenesis for Bone Tissue Engineering. J. Mater. Sci.: Mater. Med. 2013, 24, $1251-1260$

(45) Fuchs, S.; Hofmann, A.; Kirkpatrick, C. J. Microvessel-Like Structures from Outgrowth Endothelial Cells from Human Peripheral Blood in 2-Dimensional and 3-Dimensional Co-Cultures with Osteoblastic Lineage Cells. Tissue Eng. 2007, 13, 2577-2588.

(46) Lian, J. B.; Stein, G. S. Concepts of Osteoblast Growth and Differentiation: Basis for Modulation of Bone Cell Development and Tissue Formation. Crit. Rev. Oral Biol. Med. 1992, 3, 269-305.

(47) Ducy, P.; Zhang, R.; Geoffroy, V.; Ridall, A. L.; Karsenty, G. Osf2/Cbfa1: A Transcriptional Activator of Osteoblast Differentiation. Cell 1997, 89, 747-754.

(48) Jundt, G.; Berghäuser, K.-H.; Termine, J.; Schulz, A. Osteonectin-A Differentiation Marker of Bone Cells. Cell Tissue Res. 1987, 248, 409-415. 
(49) Tavian, M.; Zheng, B.; Oberlin, E.; Crisan, M.; Sun, B.; Huard, J.; Peault, B. The Vascular Wall As A Source of Stem Cells. Ann. N. Y. Acad. Sci. 2005, 1044, 41-50.

(50) Fraser, S. T.; Ogawa, M.; Yu, R. T.; Nishikawa, S.; Yoder, M. C.; Nishikawa, S.-I. Definitive Hematopoietic Commitment Within The Embryonic Vascular Endothelial-Cadherin+ Population. Exp. Hematol. 2002, 30, 1070-1078.

(51) Nishikawa, S.-I.; Nishikawa, S.; Hirashima, M.; Matsuyoshi, N.; Kodama, H. Progressive Lineage Analysis by Cell Sorting and Culture Identifies FLK1+ VE-Cadherin+ Cells at A Diverging Point of Endothelial and Hemopoietic Lineages. Development 1998, 125, 1747-1757.

(52) Vodyanik, M. A.; Thomson, J. A.; Slukvin, I. I. Leukosialin (CD43) Defines Hematopoietic Progenitors in Human Embryonic Stem Cell Differentiation Cultures. Blood 2006, 108, 2095-2105.

(53) Yin, H.; Ji, B.; Dobson, P. S.; Mosbahi, K.; Glidle, A.; Gadegaard, N.; Freer, A.; Cooper, J. M.; Cusack, M. Screening of Biomineralization Using Microfluidics. Anal. Chem. 2009, 81, 473478.

(54) Khetan, S.; Guvendiren, M.; Legant, W. R.; Cohen, D. M.; Chen, C. S.; Burdick, J. A. Degradation-Mediated Cellular Traction Directs Stem Cell Fate in Covalently Crosslinked Three-Dimensional Hydrogels. Nat. Mater. 2013, 12, 458-465.

(55) Williams, C. G.; Malik, A. N.; Kim, T. K.; Manson, P. N.; Elisseeff, J. H. Variable Cytocompatibility of Six Cell Lines with Photoinitiators Used for Polymerizing Hydrogels and Cell Encapsulation. Biomaterials 2005, 26, 1211-1218. 